\title{
WhatsApp supported language teacher development: A case study in the Zataari refugee camp
}

\author{
Gary Motteram ${ }^{1}$ (10) Susan Dawson ${ }^{2}$ (1) $\cdot$ Nazmi Al-Masri $^{3}$
}

Received: 16 December 2019 / Accepted: 19 May 2020 / Published online: 13 June 2020

(C) Springer Science+Business Media, LLC, part of Springer Nature 2020

\begin{abstract}
This paper explores the possibilities and challenges of using the social media tool WhatsApp to support language teacher development in the Zataari refugee camp in Jordan. It takes a sociocultural perspective on teacher development where WhatsApp is a mediating tool in the broader sociocultural landscape. A thematic analysis of the postings and exchanges from the WhatsApp group revealed three main uses of the WhatsApp chat: for interpersonal interactions, for professional development, and for organisational purposes. The analysis suggests the WhatsApp group contributed to the teachers' English language knowledge, provided a platform for them to share and discuss issues related to the challenges of their particular context, enabled them to contribute to the development of some teaching materials and begin to address some of the issues they had in a meaningful way. It also raises issues of participation, access, equity and sustainability. We conclude by suggesting there is good potential for the use of social media tools such as WhatsApp for teacher development in challenging contexts, despite the contextual constraints observed and described. While this specific case involves language teachers, the general findings can potentially be applied to any teacher education or training context where access to training or education might be curtailed for a number of reasons, including the most recent changes enforced by the global COVID-19 pandemic.
\end{abstract}

Keywords Language teacher development $\cdot$ Distance learning $\cdot$ Mobile learning $\cdot$ Fragile and challenging contexts - WhatsApp

Gary Motteram

gary.motteram@manchester.ac.uk

1 Manchester Institute of Education, University of Manchester, Manchester, UK

2 University of Manchester, Manchester, UK

3 Islamic University of Gaza, Gaza, Palestine 


\section{Introduction}

The current complex patterns of global migration caused by man-made conflict and natural disasters have given rise to unprecedented numbers of refugees, many of whom are living in camps. Zaatari refugee camp, the site of the present study, is the second largest in the world with approximately 78,000 people living there (World Food Program USA 2019). In refugee camps, such as Zaatari, teachers are generally underresourced, under-utilised and under-valued (Reeves Ring and West 2015). Opportunities for professional development may be limited (Kirk and Winthrop 2007), and those that do exist often lack a coherent coordination between the different NGOs and agencies who supply them (Richardson 2018). Professional development opportunities are frequently dependent on funding, and provision of basic necessities such as food and shelter inevitably take precedence (Richardson 2018). There is, however, a pressing need to find ways to support, resource and train teachers, as teachers have a central role to play in education and student learning outcomes, and are sometimes the only resource available to students (World Bank 2010). The premise of the study reported in this paper is that social media apps on readily available mobile phones might contribute to this need.

A recent literature review on teachers of refugees (Richardson 2018) highlights the lack of published research and, in particular, the lack of research into the use and effectiveness of technology in refugee contexts. There are some studies emerging from the Dadaab and Kakuma refugee camps in Kenya that examine the use of technology, and in particular, the use of social media apps by refugee teachers for professional development and support purposes. A study by Dahya et al. (2019) investigates the use of social media by refugee teachers and international trainers for supporting gender equity initiatives aimed to enhance education for girls in the camps, where the use of social media (such as WhatsApp and Facebook messaging) grew from the initial faceto-face encounters in the camps. The 'Teachers for Teachers' project in Kakuma refugee camp in Kenya also used mobile technologies to complement face-to-face teacher development activities (Mendenhall 2016). A recent paper reporting on this study focuses on the use of WhatsApp for peer mentoring (Mendenhall et al. 2018) and combines a thematic analysis of the WhatsApp group chat histories with interviews designed to explore teachers' experiences of the mobile mentoring process. The paper ends with a call for more research into the implication and impact of technology on teacher professional development in crisis contexts.

This paper responds to that challenge. The activity reported in this study, came about as a result of an Economic and Social Research Council (ESRC) Impact Accelerator Award, which aimed to explore what role mobile technologies could play in supporting language teacher development in the refugee context. In the Zaatari camp, all of the Syrian refugees employed as teachers had mobile phones, most being smart phones. However, while most teachers in the camp were using social media for personal use, they were not using it professionally, and our objective was to understand whether such tools could be used effectively for teacher development at a distance.

The social media app used in this project was WhatsApp. While WhatsApp is a tool in the broader sociocultural landscape used for a variety of different purposes, mostly social, here the adaptation is to the context of remote online teacher education in a challenging context. This paper analyses the posts and exchanges within the WhatsApp 
group itself with the aim of exploring the evidence within the WhatsApp group chat of how it was being used by the teachers and for what purposes. This is in contrast to many studies around mobile technologies that focus on teachers' perceptions and experiences rather than the actual exchanges within the group (for exceptions see Mendenhall et al. 2018 cited above; Nedungadi et al. 2017; Qi and Yuping 2017).

We begin by situating this paper in the literature on language teacher development from a broadly sociocultural perspective and in relation to fragile and challenging contexts, in particular, refugee camp settings. We then focus on the role of mobile technologies in teacher development and describe the context of the Zaatari refugee camp and the Syrian teachers who formed part of this study. We discuss our methodology with a focus on the processing and analysis of the WhatsApp chat history. Finally, we present the findings in relation to the possibilities and constraints of WhatsApp to contribute to language teacher development in challenging contexts. We conclude with a discussion of the potential role of mobile technologies in supporting teacher learning in such contexts.

\section{Literature review}

\subsection{Language teacher development from a sociocultural perspective}

Language teacher education must account for the social, cultural, political and historical context in which teaching and teacher development occur (Johnson 2006; Kumaravadivelu 2006). A sociocultural perspective understands language teacher learning and development as a 'dynamic social activity that is situated in physical and social contexts, and distributed across persons, tools and activities' (Johnson 2006: 237). It locates teacher cognition-what teachers think, know, believe and do (Borg 2003) — within the socially and historically constructed contexts in which they engage in the activity of language teaching (Cross 2010: 438). Teachers take on the role of knowledge generators not just consumers, who can 'construct their own context-sensitive pedagogic knowledge' (Kumaravadivelu 2001: 541). Perhaps this role becomes even more urgent when teachers find themselves in a physical and social context so different to the one they were initially trained to teach in or studied in themselves.

Teachers bring their knowledge and beliefs about teaching and learning from their pre-service training, their previous experience as teachers and their own experience as learners to their teaching context (Borg 2003). This might include knowledge about the content of their subject, which in the case of the present study is their knowledge of the English language, and their understandings of pedagogy; of what causes and supports teaching and learning in the language classroom (Prabhu 1990). Shulman (1987) refers to these as Content Knowledge (CK) and Pedagogical Content Knowledge (PCK). CK for English language teachers might include the syntax, semantics, morphology, phonology and so on of the language. PCK is a teacher's unique understandings of how to organise, present and adapt particular content areas for the diverse interests and abilities of the learners. PCK is important as it enables teachers to "transform their knowledge of the subject matter into a form which makes it amenable for teaching and learning." (Borg 2006: 19). 
However, a sociocultural perspective also needs to account for the relationship between CK, PCK and the sociocultural, historical and political context in which teaching occurs. For the purposes of this paper, we refer to this aspect of teacher development as Critical Pedagogic Practice (CPP). The concept of critical pedagogy is not new (Canagarajah 2005) and aims to bring about social transformation through education.

This includes asking questions about the sort of teacher I am and wish to become, about uncovering assumptions and power relationships in the classroom and beyond, and exposing discriminatory practices (Akbari 2008; Singh and Richards 2006). It is also about exploring the relationship between language and the ideologies transmitted through it (Hawkins and Norton 2009; Kumaravadivelu 2006). CPP in the language classroom includes practices such as using themes from both the wider society and the current context in class, introducing multiple perspectives on reality, and not shying away from the messy aspects of day-to-day life (Akbari 2008). CPP is a pedagogy of possibility; a pedagogy that develops in response to the needs, aspirations and experiences of the people involved in the educational experience (Freire 1970/1996; Kumaravadivelu 2001).

Reflective practice (Farrell 2007; Schön 1983) and reflexive awareness (Edge 2011) are central to sociocultural and critical perspectives on language teacher education (Mann 2005; Prabhu 1990). Reflection is both an individual and a collective process, and as teachers engage in a community of practice (Wenger 1998), they collaborate, discuss, create and engage with each other around their shared experiences and practices, and help create new understandings and develop supportive relationships (Qi and Yuping 2017). Teacher support groups are one way in which teachers can engage in critical and reflective thinking about their practices (Richards 2008: 162). However, it is important to recognise that these support groups are also shaped by the wider social, political and ideological structures, which may in turn be reproduced within the group.

\subsection{Teacher development in challenging contexts}

We stated above that fragile and challenging contexts encompass a wide range of situations including, but not limited to the refugee camps, which are the particular focus of this paper. Other contexts are those affected by conflict, natural disasters, acute poverty, and urban deprivation, as well as remote and rural areas. Much of the literature relating to teacher learning in challenging contexts is not focused specifically on language teachers, although it does provide insight into some of the general challenges.

It is argued that many teachers working in such contexts have had little or no training, few opportunities for development, and may have limited education themselves (Moon 2007). In the case of refugee teachers, they are often recruited once they arrive in a camp, and they too may have little training or experience, basing their pedagogy on their own experience of school (Kirk and Winthrop 2007). Evidence from the Kakuma refugee camp in Kenya shows that only $31 \%$ of teachers had received any sort of training, and this training may have been as little as a one-day workshop (Mendenhall 2016). While there may be various training and development opportunities in camps, these are generally one-off and ad hoc, organised by different NGOs and agencies with little collaboration between them (Richardson 2018). Training is seen as 
a key factor in enabling generally untrained volunteer and volunteered refugee teachers to approach the classroom with a certain degree of confidence and to function with some degree of effectiveness (Winthrop and Kirk 2002).

For those who were teachers before arriving in the camp, the challenges might be very different to those they faced in their previous institutions, and they need to understand and adapt to their current context. They might need to develop skills in managing and dealing with traumatised students, training on dealing with potentially conflictive situations in the classroom, and training in dealing with large, mixed-level and mixed-age classrooms (Richardson 2018). We stated above that what teachers think, know, believe and do is situated in the context in which teaching and learning takes place. As that context changes, teachers need support to adapt and change not only to their own individual circumstances, but also to those of their learners.

With respect to English language teachers, many of those who find themselves teaching English in difficult and challenging circumstances, or having to teach other curricular subjects through English, say they lack both the language and pedagogical skills necessary for the job. A recent study amongst Syrian refugee teachers in Lebanon, found that many wanted further professional development opportunities, and in particular referred to their need to improve their English language abilities (Karam et al. 2017). In another challenging context, albeit not a refugee one, language teachers working on the Underprivileged Children's Education Programme in Bangladesh had no teaching qualification, and there was a recognised need for teacher training and the development of English-language proficiency and communicative teaching skills (Shohel and Power 2010). A baseline survey of 2000 English language teachers in Pakistan, where the challenges are resource and security related, showed that $30 \%$ had no English language skills at all (Motteram 2019).

While professional development is seen as vitally important for teachers in challenging and fragile contexts, in developing countries it is rare or ad hoc (Reeves Ring and West 2015). Given the shortage of resources and opportunities in such contexts, it seems that mobile technologies might help provide a way forward (see for example, Burde et al. 2015).

\subsection{The use of mobile technologies for teacher learning}

Technology use in education is potentially transformative (Devlin and McKay 2016), and there are a growing number of studies investigating the role of mobile learning and online communities in teacher professional development. While many studies focus on teacher education programmes and informal teacher learning in the global north (see for example Baran and Cagiltay 2010; Baran 2014; Qi and Yuping 2017), there is a small, yet growing body of work exploring the potential of digital technologies for teacher professional development in challenging contexts (McAleavy et al. 2018). In refugee contexts, there is evidence that technology is increasingly being used for teacher training and development purposes, but there is a lack of research into its effectiveness (Richardson 2018: 53).

While other digital tools are discussed in this literature, the predominant technology is the mobile phone. Studies that focus on mobile learning include language teacher development (Shohel and Power 2010); teacher support and mentoring (Mendenhall 2016; Mendenhall et al. 2018), science teacher support (Kumar Singh 2017); teacher 
education (Habibi et al. 2018); general education (Nedungadi et al. 2017), including equity education (Dahya et al. 2019), and medical education (Barteit et al. 2018). Another recent study looks at the relationship between resilience and WhatsApp for language teacher professional development in remote and rural areas of sub-Saharan Africa (Motteram and Dawson 2019). These studies show how mobile learning has been used to address the need for appropriate, context-specific, and relevant developmental opportunities for those teachers who work in challenging educational contexts, such as remote and rural locations, contexts affected by conflict, and refugee camps.

For example, in rural India, where lack of quality teachers and teacher absenteeism is a major challenge for rural schools (Nedungadi et al. 2017), technology, and specifically WhatsApp, was used to provide professional development opportunities that were otherwise unavailable, and also to support and monitor teachers. Initially, just the chat function of WhatsApp was used, but this was extended as the project progressed to utilise other features: time-stamped photos taken of the class each day monitored teacher and student attendance; teachers posted videos of themselves teaching a concept and received support and feedback from central coordinators; and teaching resources were posted in WhatsApp which could then be downloaded by teachers onto tablets and shared with students. In this study, both teachers and students were provided with Android tablets. WhatsApp has also been used by a group of science teachers in a deprived district in south-west India where teacher morale was generally low and little support was available. A weekly discussion group in WhatsApp for about 30 teachers on a topic chosen by them aimed to address conceptual gaps they had identified, and served to build confidence in different teaching methods and in content knowledge (Kumar Singh 2017).

These studies illustrate how online and mobile learning can help overcome issues of geographical isolation, such as a lack of resources and development opportunities (see also Baran and Cagiltay 2010: 80). Mobile learning provides flexibility for teachers and the potential for 'collaborative, contextualized, customized, and personalized learning opportunities' (Baran 2014). It allows teachers to share resources, reflect on their own practice through the questions and shared experiences of others, develop new understandings through the articulation of their own experiences, and collaborate in the creation of artefacts for teaching and learning purposes (Macià and García 2016).

However, the use of mobile technology is not without its issues. The project cited above in the Kakuma refugee camp in Kenya (Mendenhall et al. 2018) which used WhatsApp to provide mentoring and a platform for the exchange of ideas between the teachers, provided each teacher with a mobile phone and data as part of the project. When phones were lost, stolen or broke, teachers either had to use their own phones (and were not always able to retrieve their WhatsApp data), or they needed to wait for a replacement phone from the project. Connectivity and the cost of mobile data were also highlighted as an issue in this project. This raises questions about sustainability - what happens when the project ends and teachers need to fund their own data? - and also equity - is there equal access to affordable data for all?

Other issues arising from the use of mobile technologies in challenging and fragile contexts include a lack of support in using the technology and general ICT competency (Chipps et al. 2015; Shohel and Power 2010); difficulties in accessing computers and internet (Baran and Cagiltay 2010), and finding time and space for this type of professional development (Shohel and Power 2010). The time commitment for those 
who lead and mentor through social media apps such as WhatsApp has also been raised (Mendenhall et al. 2018; Motteram and Dawson 2019).

There is therefore some evidence of both the possibilities and constraints of teacher development through mobile technologies. However, before we move on to discuss the specific methodology used to process and analyse the WhatsApp chat history and examine how the teachers in this study used WhatsApp, it is important to understand who these teachers were and the sociocultural landscape in which they were living and in particular, the teaching and learning context in order to situate both the analysis and the findings of this study. The context described below is based on field notes and documentary evidence which formed part of the main project research design (see Motteram et al. 2020 for a detailed explanation of this work).

\section{Context}

The Zaatari refugee camp in northern Jordan is close to the Syrian border, and with 78,000 residents it is the largest town in Jordan. Approximately $50 \%$ of these refugees are children (World Food Program USA 2019).

The Syrian teachers, recruited by NGOs working in the camps, teach in what is termed the 'informal school'. Syrian children go to two schools in the camp: one follows the Jordanian education system and the children are taught by Jordanian teachers who come into the camp every day from outside; the second school is staffed by the Syrian teachers and is a support school to try to bring the children up to the level of the Jordanian system. The classes that the teachers teach are run along gender lines and the teachers work in the mornings or afternoons according to their gender and the gender of the classes. For English, which is the focus here, the Syrian education starts English language learning later than in Jordan, so even if the children have not lost time in education as the result of the dislocation caused by the Syrian crisis, they need to 'catch up' in order to have a chance of passing the end of school examination that will give them access to further and higher education in Jordan.

As stated above, all the Syrian teachers in this project had a mobile phone, with most accessing the internet through mobile data purchased in the camp. Wireless internet access in the camp is controlled by the Jordanian authorities, and NGOs are actively discouraged from allowing Syrians access to this service. Where access is available, it is generally limited.

\section{Methodology}

The main data set drawn on for the purposes of this paper is the chat history of a WhatsApp group created by and for the Syrian teachers in the project. WhatsApp was chosen for the purposes of this present study for several reasons: WhatsApp is a social network application that is widely used for instant messaging, photo, video and audio sharing; it was the preferred social media tool for the teachers we were working with making it a locally appropriate tool; it is low cost and low tech; once downloaded it can be used through an internet connection, either wireless or making use of data packages; all exchanges are encrypted; the chat history can be downloaded as a text file with all of 
the accompanying media, which means the text can be manipulated for analytical purposes. As our aim was to understand how (if at all) WhatsApp might facilitate and support language teacher development, our guiding question for the purposes of this paper is: In what ways (if any) does the WhatsApp group chat contribute to language teacher development?

\subsection{Participants and data set}

In the Zaatari camp at the time of the study, there were 27 Syrian English teachers or trainers of other subjects who were part of a course run face-to-face by the British Council (11 females and 16 males). In a needs analysis survey conducted at the beginning of the project, the teachers' reported their experience as varying between 3 months and 14 years, although the range of their refugee camp teaching experience was between 3 months and 4 years. The classes taught by the teachers included primary, secondary and adult. Class sizes reportedly varied from 10 to 90 students, although Author one on his visits never saw classes bigger than 30 .

The WhatsApp group, which was created by one of the Syrian teachers on 25th April 2017, was active for a period of almost 7 months to 19th November 2017 when activity stopped. There were 27 teachers who could have joined the WhatsApp group, and 18 of these chose to take part. In addition, the group included the four researchers and one British Council trainer who joined the group in October. This made a total WhatsApp community of 23 people. It is the chat history of this WhatsApp group that is analysed below.

The project was reviewed by The University of Manchester (UK) ethical committee before data collection started. All of the participants were given information sheets (provided both in English and Arabic) about the project and all of the participants signed consent forms to give the researchers permission to collect and analyse the data used here.

\subsection{Processing and analysing the WhatsApp data}

The WhatsApp group chat history was exported as a text file. The text file was manually cleaned and manipulated so that it could be imported as a .csv file to Excel. There were 1219 individual posts in the chat. Each post was initially categorised according to its function within the context of the chat, such as 'Greet other participants', 'Arrange a meeting', 'Describe a teaching problem', 'Share a link', 'Add user' and so on. Each function identified was also briefly described to clarify the context of that function. For example, 'Arrange a meeting' referred to 'arranging meetings in Jordan or via Skype'. This initial stage provided familiarisation with the data, and an overview of different aspects of the chat. Some of these functions covered a variety of different themes. For example, 'Offer help' included offers of help with translation from Arabic to English, an offer to provide reading material, and an offer to find an online source for something.

The second analytical phase can be described as a thematic analysis: 'a method for identifying, analysing and reporting patterns (themes) within data' (Braun and Clarke 2006: 79). For this stage, all posts that related to adding or removing users and number 
changes were removed before the analysis was done, and each of the remaining 1167 posts was coded thematically. This was an iterative process of initial thematic coding, writing descriptive labels for each code, checking for duplicates, similarities and so on, recoding and checking until a final total of 14 thematic codes were identified and described in the Syrian teachers' data set (Fig. 1). These codes were then further grouped into three main overarching themes: Interpersonal interactions, Development, and Organisation (Fig. 1). Descriptive statistics generated in both Excel and SPSS were also used to explore, for example, the use of WhatsApp over time, how different people contributed, and so on.

The third analytical stage looked in more detail at groups of posts under the 'Development' theme, which helped us explore our guiding question. This was a deductive analysis based on three categories that emerged from the literature as discussed above: Content Knowledge (CK), Pedagogical Content Knowledge (PCK) (Shulman 1987) and Critical Pedagogic Practice (CPP). We looked for evidence of how (if at all) the teachers were building their knowledge of the English language (their $\mathrm{CK}$ ), their understanding of context specific PCK, and their critical awareness of the relationship between their practice and the wider social, historical and political context (CPP) through the WhatsApp group.

\section{Findings}

This section explores the findings of both the descriptive statistics and the thematic analysis of the WhatsApp chats.

\subsection{How the chats were used}

The number of posts made by each participant throughout the chat history is shown in Table 1 . The majority of posts $(43.5 \%)$ were made by Author one, who was the main moderator of the group. Two of the Syrian teachers (one male and one female) contributed substantially to the group (125 and 145 posts respectively), but the majority

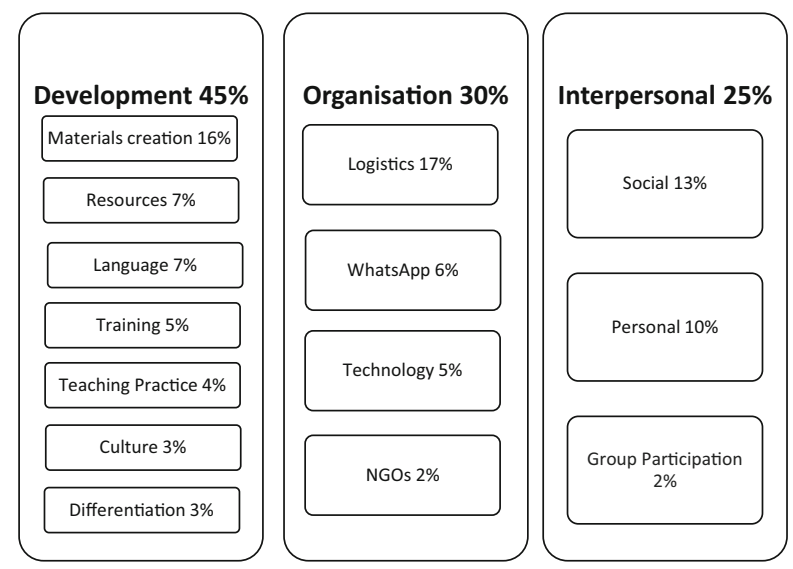

Fig. 1 Distribution of thematic codes 
Table 1 Contributions by participant

\begin{tabular}{|c|c|c|c|}
\hline & Number of contributions made & Number of participants & Percentage of total contributions \\
\hline & Less than 10 & 9 & $3.7 \%$ \\
\hline & 11 to 20 & 6 & $7.0 \%$ \\
\hline & 21 to 50 & 2 & $5.0 \%$ \\
\hline & 51 to 100 & 3 & $17.7 \%$ \\
\hline & 101 to 150 & 2 & $23.1 \%$ \\
\hline & More than 500 & 1 & $43.5 \%$ \\
\hline Total & 1167 & 23 & $100 \%$ \\
\hline
\end{tabular}

(15 participants) made very few posts ( 20 or fewer). Of the nine participants who made 10 or fewer posts, two were research assistants to the project (nine and three posts respectively), one Syrian teacher made two posts, one made three, two made five, two made seven and one made nine posts. The other researcher in the project (Author three) made 34 posts. The three Syrian teachers who contributed between 50 and 100 posts, made 52, 62 and 87 posts each.

Author one was responsible for more than 500 posts. $42 \%$ of these were coded under 'Development', $40 \%$ under 'Organisation', and 18\% 'Interpersonal'. The majority of those coded under 'Organisation' related to his own visits to the camp and the logistics surrounding that.

Figure 1 shows the sub themes in relation to these overall themes for all the posts in the group. The percentage of contributions for each overall theme and sub theme is also shown.

Our main concern in this paper is to explore how a WhatsApp group chat might contribute to a teacher's professional development, and Fig. 1 shows that just under half of all posts in the chat were directly concerned with various aspects of teacher development. The most frequently discussed theme was related to the possibilities for and creation of materials that were context appropriate, and ideas for lesson plans using those materials. The availability of local resources and how these were being used and adapted, or rejected, by the teachers was also a relatively important part of the chats. Questions about language and language development also figured relatively frequently within this theme allowing the teachers to develop their language knowledge and skills. They also discussed and reflected on their learning from the face-to-face training sessions with both the British Council and Author one, and previous courses that they had attended. Other themes involved discussing issues around understanding British culture and literature, practical strategies for teaching practice, and in particular, how to deal with the mixed levels in classes through differentiation. This seemed to be an important issue for the teachers and was therefore coded as a distinct theme in its own right.

It is important to understand the role of Author one here as he contributed $42 \%$ of the posts coded under Development. As the main mentor of the group, his role was to encourage the Syrian teachers to discuss issues they were facing in their classrooms and help them explore locally and contextually appropriate responses. Many of these posts were asking the Syrian teachers questions about the reality of their classrooms, asking for clarification on statements the Syrian teachers were posting, encouraging them to share the materials and resources they were talking about, asking questions to help 
them develop their lesson plans and find their own solutions to issues emerging from the teaching and learning context.

More than half of the posts related to the organisation and interpersonal themes. Much of the organisation category was concerned with the logistics of arranging transport, access to the camps, and meeting places in relation to Author one's visits to the camp. There were discussions about various issues relating to working for the various NGOs, and posts around issues of connectivity and technology. There were also posts related to the use of WhatsApp itself (6\%), for example, how to make someone an administrator, and whether to split the group or combine it with other groups they knew about.

The Interpersonal included social messages (greeting, encouraging, exhorting), personal messages (between two particular chat participants, but non-teaching and learning related) and messages which served to manage and stimulate participation within the group. The latter were generally initiated by either Author one or one particular teacher in the group who was keen to encourage as many teachers as possible to contribute opinions and ideas.

Having described the different ways in which the WhatsApp chat was used by the Syrian teachers and others, we now move on to look in more detail at the ways in which the WhatsApp group facilitated various aspects of the teachers' professional development.

\subsection{Teacher development in the WhatsApp chat history}

As described in the analysis section above, we used a basic framework derived from the literature (Content Knowledge; Pedagogical Content Knowledge and Critical Pedagogic Practice) to look for evidence of teacher development.

\subsubsection{Content (language) knowledge}

The WhatsApp chat has various examples of teachers developing their linguistic understanding and knowledge through the text-based communications afforded by the tool. There were questions about vocabulary, the meaning of a certain phrase, syntax, and also questions about pragmatics. For example, for one of the Syrian teachers, exposure to a new word ('yeah') used by another teacher in the chat in response to his question, expands his understanding of register, and thus his linguistic knowledge (Table 2).

This exchange also illustrates how LL is beginning to discover that the formal, textbook English he has learnt is not sufficient for all his needs. His last comment seems to express a sense of frustration towards what he sees as different types of English which he needs to discover and then learn. Both his previous experience of language learning and his current context do not seem to have provided him with exposure to informal, spoken English. The text chat, which resembles spoken rather than formal written English has the potential to furnish him with those opportunities. Perhaps the exchange also raises questions about the version of English often represented in course books, the ideologies underlying that representation of English, and its subsequent usefulness to learners of English in our increasingly globalised world. 
Table 2 WhatsApp conversation 1

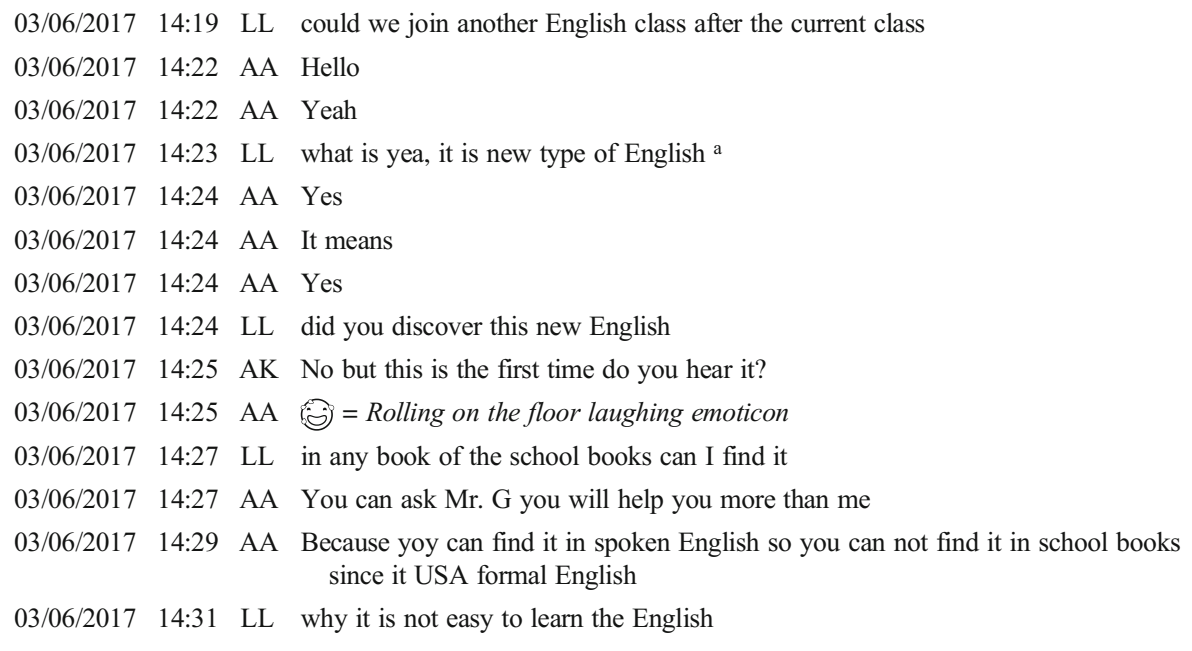

a The text chat is quoted as it was typed, no corrections are made

\subsubsection{Pedagogical content knowledge}

PCK knowledge focuses on the 'how' of teaching, and the WhatsApp chat provided a space for the Syrian teachers to share their classroom practices, and to request help with some of the struggles and problems they were facing in their classes.

The following exchange is part of a long discussion by the Syrian teachers on a common classroom issue they were facing: how to deal with mixed-levels in their classes (Table 3).

ML describes the difference in language ability between the learners in her class, and her attempts to support the weaker students with additional grammar explanations at the

Table 3 WhatsApp conversation 2

\begin{tabular}{|c|c|c|c|}
\hline $04 / 05 / 2017$ & 18:56 & ML & $\begin{array}{l}\text { I have many levels in one class .how I can help the weak students with out effect } \\
\text { the good students }\end{array}$ \\
\hline $04 / 05 / 2017$ & 19:01 & ML & Some students don't know even the letters and some of them don't know the tenses \\
\hline $04 / 05 / 2017$ & 19:02 & ML & Reported speach for example. \\
\hline $04 / 05 / 2017$ & 19:04 & GY & So some are beginners and some have some language, is that what you mean? \\
\hline $04 / 05 / 2017$ & 19:04 & GY & So, what materials do you use with this class, now? \\
\hline $04 / 05 / 2017$ & 19:04 & GY & What teaching would you do? \\
\hline $04 / 05 / 2017$ & 19:11 & QM & I think we need more than one way to deal with that problem. \\
\hline $04 / 05 / 2017$ & 19:17 & ML & $\begin{array}{l}\text { I tried to gave the weak students supporting lessons to explain the tense at the } \\
\text { beginning then referred it to reported speach }\end{array}$ \\
\hline $04 / 05 / 2017$ & 19:17 & QM & We have to divide them and give every group what they need \\
\hline $04 / 05 / 2017$ & 19:19 & ML & I did it but the good students were not satisfied \\
\hline
\end{tabular}


beginning of the class. However, as she reflects briefly on this experience in response to QM's suggestion for differentiation, she suggests that in her attempt to support the weaker students, she failed in some way to meet the learning expectations of the stronger ones who responded negatively to her intervention. The reasons for this negative response and how it was evidenced in her classroom are not explored specifically in the chat, yet it illustrates her desire to find ways to develop contextually appropriate ways of dealing with the context specific issues she is facing.

As a group they decided to try and create a differentiated lesson plan with corresponding materials. They agreed that a good starting point for this lesson plan would be a story. AA offers a suggestion: 'The story that talk about (Lion and the meat) it's suitable for students' and QM asks her to write it (Table 4).

This exchange is not just a response to the request to 'write the story'. AA 'tells' the story through the chat medium. This exchange has remarkable similarities to a classroom exchange. AA takes on the role of 'teacher', eliciting ideas from the class, while ID (and later in the story, EM) participate as active 'learners', asking questions and offering comments. In fact, it is one of the 'learners' (ID) who initiates the interactions.

The story continues: (Table 5)

The use of emojis by the 'learners' may replicate what might have been a physical response in the actual classroom. Perhaps this illustrates the potential of the chat format used synchronously to practise, and even model, certain classroom techniques, thus building PCK. Such exchanges could potentially be followed up with a discussion about classroom techniques such as elicitation.

\subsubsection{Critical pedagogical practice}

Teacher development is more than learning teaching methods and techniques. It also involves understanding the values, assumptions and so on that are embedded in our methodologies and materials (Singh and Richards 2006). Before AA told the story of the 'Lion and the meat', QM had suggested another story entitled 'Love and anger have no limits' where a father used violence against his son. Despite liking the story, the teachers had rejected it because of the impact it might have on father-son relationships among their learners. Although not made explicit in the chat, perhaps this reluctance also stemmed from

Table 4 WhatsApp conversation 3

\begin{tabular}{|c|c|c|c|}
\hline 08/05/2017 & $19: 52$ & AA & $\begin{array}{l}\text { It's about a proud lion which is the king of the jungle, and while this lion was } \\
\text { sleeping there was a hungry mouse was walking and searching for food }\end{array}$ \\
\hline $08 / 05 / 2017$ & $19: 53$ & AA & Suddenly the mouse found a piece of meat in front of the sleeping lion \\
\hline 08/05/2017 & 19:54 & AA & The mouse climb on the back of the lion to take the meat but \\
\hline $08 / 05 / 2017$ & $19: 54$ & AA & Unfortunately the lion wake up \\
\hline $08 / 05 / 2017$ & $19: 55$ & ID & What did he do? \\
\hline 08/05/2017 & 19:55 & AA & What do you think? \\
\hline 08/05/2017 & 19:56 & ID & Ask her a question? \\
\hline 08/05/2017 & 19:56 & AA & I want to raise your suspension \\
\hline 08/05/2017 & 19:56 & ID & What do you want from me? \\
\hline $08 / 05 / 2017$ & $19: 57$ & ID & Asked he!!! \\
\hline
\end{tabular}


Table 5 WhatsApp conversation 4

\begin{tabular}{|c|c|c|c|}
\hline 08/05/2017 & 19:58 & AA & $\begin{array}{l}\text { The lion asked the mouse (what are you doing? that's my meat! } \\
\text { Are you stealing my meat?) }\end{array}$ \\
\hline $08 / 05 / 2017$ & $19: 59$ & ID & And then what?? \\
\hline 08/05/2017 & 20:00 & $\mathrm{AA}$ & $\begin{array}{l}\text { The mouse said lm very hungry but } 1 \mathrm{~m} \text { sorry please don't kill me } \\
\text { and let me go } 1 \text { will help you one day }\end{array}$ \\
\hline 08/05/2017 & 20:00 & $\mathrm{AA}$ & The lion answered proudly \\
\hline 08/05/2017 & 20:01 & ID & I am sure he let it go \\
\hline $08 / 05 / 2017$ & 20:02 & AA & (How could you help me? you are small and $1 \mathrm{~m}$ stronger than you \\
\hline $08 / 05 / 2017$ & $20: 02$ & ID & $\begin{array}{l}\text { What a proud lion!!! } \\
\qquad=\text { Lion emoji }\end{array}$ \\
\hline 08/05/2017 & 20:03 & $\mathrm{AA}$ & You have made me laugh but I won't kill you go away \\
\hline 08/05/2017 & 20:03 & $\mathrm{AA}$ & and don't come back \\
\hline 08/05/2017 & 20:05 & $\mathrm{AA}$ & $\begin{array}{l}\text { next day while the lion was walking in the jungle, he felt a rope } \\
\text { around his leg and was hanging from a tree }\end{array}$ \\
\hline 08/05/2017 & 20:05 & EM & The lion decided to let the mouse go \\
\hline 08/05/2017 & 20:05 & $\mathrm{AA}$ & He was in a trap \\
\hline $08 / 05 / 2017$ & $20: 06$ & EM & $\Delta=$ Thumbs up emoji \\
\hline 08/05/2017 & 20:07 & $\mathrm{AA}$ & $\begin{array}{l}\text { and shouting for help then the little mouse hear him and } \\
\text { said (don't worry } 1 \text { will help you }\end{array}$ \\
\hline $08 / 05 / 2017$ & 20:09 & EM & (િ) $=$ Smile emojis \\
\hline 08/05/2017 & 20:09 & EM & After he started to laugh \\
\hline $08 / 05 / 2017$ & 20:09 & $\mathrm{AA}$ & $\begin{array}{l}\text { the mouse ran and bring all his friends and the mice bit } \\
\text { through the rope and cut it }\end{array}$ \\
\hline $08 / 05 / 2017$ & $20: 10$ & AA & And the lion was free again \\
\hline $08 / 05 / 2017$ & $20: 11$ & AA & Finally the lion and the mice became good friends \\
\hline
\end{tabular}

their own reality of escaping and witnessing conflict and the possible resulting trauma from that (see for example Burde et al. 2017). In contrast, AA's story seems to reflect the sort of values and wisdom they wish to convey to their students, such as cooperation, friendship, tolerance and self-belief, as is seen in the continuation of the above exchange (Table 6).

Although examples such as this are not frequent in the data, it does suggest the potential of such chats, perhaps as trust increases between participants, for teachers to

Table 6 WhatsApp conversation 5

\begin{tabular}{llll}
\hline $08 / 05 / 2017$ & $20: 12$ & ID & I think it is good for students to conclude wisdoms from the story \\
$08 / 05 / 2017$ & $20: 12$ & EM & That's really a nice story for children \\
$08 / 05 / 2017$ & $20: 12$ & AA & and they lived happily forever \\
$08 / 05 / 2017$ & $20: 12$ & AA & Yeah \\
$08 / 05 / 2017$ & $20: 12$ & AA & The moral from this story is \\
$08 / 05 / 2017$ & $20: 13$ & ID & It makes them like cooperation friendship ...etc \\
$08 / 05 / 2017$ & $20: 14$ & ID & Donot belittle others \\
$08 / 05 / 2017$ & $20: 15$ & AA & Don't be proud of yourself because no matter how small \\
& & & you are, you can do important things \\
\hline
\end{tabular}


Table 7 WhatsApp conversation 6

\begin{tabular}{llll}
\hline $06 / 06 / 2017$ & $20: 15$ & QM & I feel these books make me a "robot" \\
$06 / 06 / 2017$ & $20: 27$ & QM & A red robot!!!! \\
\hline
\end{tabular}

begin to explore their own assumptions, values and ideologies and those embedded in the contexts they are working in. It also suggests a pedagogy of hope and possibility (Freire 1970/1996; Kumaravadivelu 2001), as the teachers enable the learners to explore possibilities for change.

Reflection can play an important role in developing deeper understandings of one's practice, helping reveal beliefs and assumptions (Elliott 2009). Attending to feelings is one aspect of reflection (Boud et al. 1985). The following contributions illustrate how QM, another Syrian teacher, expresses his feelings towards the text books they have been given, which are red in colour, using the metaphor of a robot (Table 7).

The 'red' books seem to make his teaching feel mechanical and robotic. They reduce his creativity, and impact on his agency as a teacher and stop him being the teacher he wishes to be. Perhaps his 'sense of plausibility' (Prabhu 1990) as a teacher is diminished; that sense of knowing what makes teaching and learning happen in the classroom, and having the agency to practice those beliefs. QM was very vocal in the chat about the need for the teachers to create materials that were more suitable for their needs. Again, this illustrates a latent ability among the teachers to question their teaching lives within the refugee camp context, and to respond appropriately to that.

\subsection{Understanding the wider sociocultural context}

A sociocultural perspective encourages us to look at teacher development through the lens of the wider political, historical and cultural context. There was perhaps understandably, given the geopolitical situation from which these teachers and their students had come, little discussion of these broader issues in the WhatsApp group. One teacher made several attempts to initiate debates of a political, religious and historical nature, but the other teachers did not engage with him, which perhaps raises questions about how and for what purpose the WhatsApp group might be used, and the need to keep it focussed on professional development issues. The data presented in this section therefore relates to the immediate teaching context and the technological infrastructure available.

\subsubsection{Syrian teachers' changing context}

We referred to the issue of mixed-level classes highlighted by the Syrian teachers above, and discussions around differentiation and creating materials and lesson plans to address that was a significant part of the development theme. QM gives a small insight into why this was such a pressing issue for these teachers (Table 8).

Table 8 WhatsApp conversation 7

07/06/2017 15:14 QM The organisation is not as school we face different types of student


Table 9 WhatsApp conversation 8

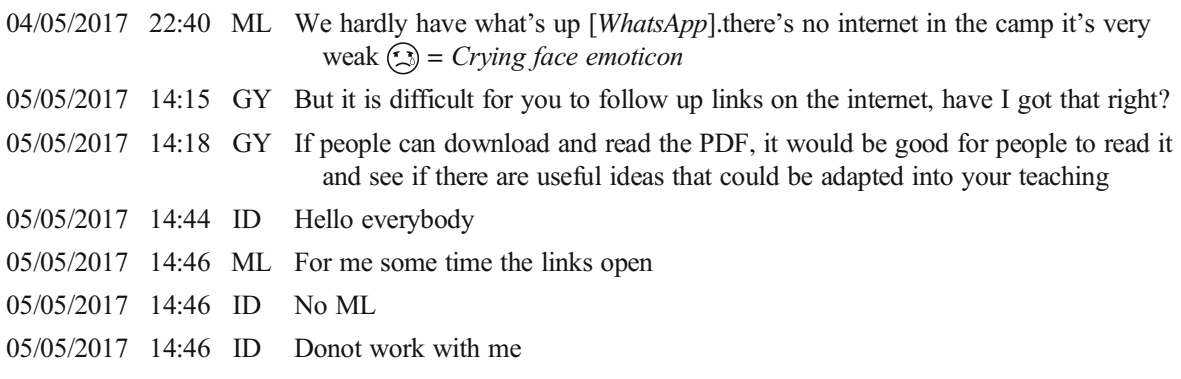

He compares his current teaching context to his previous one where presumably there was more homogeneity of levels in the classes. This perhaps reflects his own sociocultural trajectory, his background of teaching in Syria, where learners of similar ages are more likely to have similar levels. There is a need for new and different approaches, not only because of the variety in each class, but also 'because every course is different from others' (QM). The teachers need to be adaptable and resourceful in their situation, yet in a context of 'forced immobility' (Fassetta et al. 2017) their ability to access what they need is limited.

WhatsApp allows for the sharing of files and resources, yet because of the weak signal in the camp, coupled with the limited internet access allowed to Syrians, the teachers found it difficult to access outside resources despite their possession of a mobile device (Table 9).

The exchange illustrates the unreliability of internet access for these teachers, and almost all links were shared by the researchers rather than the Syrian teachers themselves. This is one of the constraints of the Zaatari refugee camp context and a frustration for the teachers in attempting to use WhatsApp for their professional development.

\section{Discussion}

As would be expected, in some areas the themes are similar to other studies. There is a considerable amount of interpersonal engagement in our data with $25 \%$ of the exchanges being coded to this theme. This is likely both to reflect the original function of WhatsApp, as a social media tool, but also the necessary socialisation that is recommended in any form of online group learning activity. The term that is used to describe this form of socialisation in the online and distance learning literature is 'social presence' (Lowenthal and Dennen 2017) and making this happen is a challenge in online courses. Social presence is often linked to Moore's concept of transactional distance (Moore 1993), which he used to describe some of the fundamental differences between distance and face to face learning. However, what the data shows here is that using social media tools that are designed to encourage engagement and social presence can perhaps be a barrier to online learning for different reasons. We inhabit a world dominated by social media and people are used to using it for social exchange rather 
than the professional focus that we are attempting here. Moving a group away from the more social aspects of such apps towards the professional whilst maintaining social presence therefore needs further exploration.

While 23 people were members of the group, the bulk of the discussion is initiated and engaged in by a limited number of the participants. This is common in other online communities, where only a small percentage of members post and up to $90 \%$ are observers who do not actively contribute themselves (Kyounghye and You-Kyung 2013: 238). This also aligns with a finding of another study of the use of WhatsApp to support teacher development in a refugee camp, where mentors expressed the difficulties they had in getting their mentees to participate actively in the WhatsApp groups (Mendenhall et al. 2018). As our analysis was based entirely on the content of the WhatsApp group chat, we do not know why other teachers did not post much. However, messages posted in the chat highlight the internet access issues for some of the Syrian refugee teachers in this study, a finding consistent with the Kakuma refugee camp project (Mendenhall et al. 2018). We do not know if better access would have increased engagement. Certainly, when Author one visited the camp there was good attendance at the sessions he organised and the teachers appeared very willing to take part in the proposed project (see Motteram et al. 2020 for a more detailed presentation of what happened in the face-to-face phases of the ESRC project). Perhaps this also suggests that WhatsApp may be most usefully used as one of several means of professional development, rather than the sole means (Mendenhall et al. 2018).

Peripheral participation can also be a prior step to more active involvement (Wenger 1998), and had the group run for longer, there is the possibility that more teachers would have got involved (Macià and García 2016: 301). Our analysis showed that Author one was responsible for $43.5 \%$ of the contributions and thus played a key role in encouraging participation. Again, had the group run for longer, would this pattern have continued or remained the same? This also raises questions around the time investment by those who mentor and administer WhatsApp groups. A study from sub-Saharan Africa shows that those who took the responsibility for organising and running WhatsApp groups for professional development in remote and rural contexts highlighted the time-consuming nature of the task (Motteram and Dawson 2019). Similar findings were reported by the international instructors running WhatsApp groups in the Kenyan refugee camps (Dahya et al. 2019). This has implications for the sustainability of such groups in the long term and how responsibility might be shared by different group members. Teachers need to see this not only as a valid and useful way of developing professionally but also want to participate in the responsibility for the functioning of that group through their contributions.

The Syrian teachers are literally trapped in the context where they live and work and while engagement was limited by the sociocultural realities of that context such as lack of resources, limited internet connectivity, and institutional and political constraints, the WhatsApp group provided a space for the Syrian teachers to pose questions, ask for help, articulate their practice and learn from others' experiences (Macià and García 2016: 294, 301). There is evidence of the development of Content Knowledge (CK), where the teachers discuss aspects of language, and the development of Pedagogical Content Knowledge (PCK) through sharing resources and ideas for teaching practice, requesting specific help with an element of teaching, and collaborating in the creation of classroom resources (Shulman 1987). Encouraging collaboration is seen as central to 
the success of professional development in challenging contexts (Burns and Lawrie 2015). There is also some burgeoning evidence of Critical Pedagogic Practice through the discussion of contextually relevant and potentially transformative topics such as the Lion and the Mouse story (Akbari 2008).

The approach taken in this paper to analysing the actual data of the WhatsApp chat in detail has highlighted the methodological and analytical possibilities for researching teacher professional development through social media apps (see also the analysis of WeChat group for teacher professional development Qi and Yuping 2017). However, it also highlights the complexity of the issues involved in providing professional development opportunities in fragile contexts. Sustainability was an underpinning principle of this project and encouraged the use of local assets and tools (for example, teachers' own mobile phones and WhatsApp) rather than importing technology from outside. However, the intermittent and controlled internet access in the camps raised issues of access and equity. Without regular access to a reasonable internet connection or stable mobile data network for all teachers, even the use of readily available and low cost technology may accentuate differences in opportunity and structural injustices in the system.

\section{Conclusions}

The findings of this study suggest that there are important opportunities for the kind of teacher development practices that have been presented going forward. This paper is exploratory in nature and is an initial and novel attempt to analyse the actual data of a WhatsApp group and the postings and exchanges within it in order to try and understand how such a group might contribute to teacher professional development in challenging contexts, such as a refugee camp. Recent literature has strongly suggested that mobile teacher development is a possible way forward in refugee and other similar contexts and this study has shown that such activity is certainly possible and current work is building on the findings here. However, it has also highlighted some of the challenges including: participation and engagement by all in the group; the move from using WhatsApp for social interaction to using it for professional purposes; and contextual issues of internet access potentially reinforcing inequalities. Further studies are needed to examine how teacher development might happen over a longer time-scale and how teacher participation develops and changes over time. There is also scope to further explore the potential of such a group in the collaboration and production of contextually appropriate materials, teacher language development, and sharing, exploring and addressing issues and problems that arise in the context. Issues of access, equity and sustainability when using technology for teacher professional development in fragile and challenging contexts also need further exploration. Technology and social media apps are not the panacea for teacher professional development in fragile contexts, but as the world moves increasingly online in the current context of the COVID19 pandemic, their potential, relevance and importance will surely continue to increase rather than decrease.

Acknowledgements The project reported on in this paper was funded by an Economic and Social Research Council Impact Accelerator Award. 


\section{References}

Akbari, R. (2008). Transforming lives: Introducing critical pedagogy into ELT classrooms. ELT Journal, 62(3), 276-283. https://doi.org/10.1093/elt/ccn025.

Baran, E. (2014). A review of research on Mobile learning in teacher education. Journal of Educational Technology \& Society, 17(4), 17-32. https://doi.org/10.1007/s10639-011-9182-8.

Baran, B., \& Cagiltay, K. (2010). Motivators and barriers in the development of online communities of practice. Eurasian Journal of Educational Research, 39, 79-96.

Barteit, S., Jahn, A., Bowa, A., Lüders, S., Malunga, G., Marimo, C., Wolter, S., \& Neuhann, F. (2018). How self-directed e-learning contributes to training for medical licentiate practitioners in Zambia: Evaluation of the pilot phase of a mixed-methods study. JMIR Medical Education, 4(2), e10222. URL: https://mededu. jmir.org/2018/2/e10222. https://doi.org/10.2196/10222.

Borg, S. (2003). Teacher cognition in language teaching: A review of research on what language teachers think, know, believe, and do. Language Teaching, 36(2), 81-109. https://doi.org/10.1017 /S0261444803001903.

Borg, S. (2006). Teacher cognition and language education: Research and practice. London: Continuum.

Boud, D., Keogh, R., \& Walker, D. (1985). Promoting reflection in learning: A model. In Reflection: Turning experience into learning (pp. 18-40). London: RoutledgeFalmer.

Braun, V., \& Clarke, V. (2006). Using thematic analysis in psychology. Qualitative Research in Psychology, 3(2), 77-101.

Burde D, Guven O, Kelcey J, Lahmann H and Al-Abbadi K (2015) What works to promote children's educational access, quality of learning, and wellbeing in crisis-affected contexts. Education Rigorous Literature Review: Department for International Development.

Burde, D., Kapit, A., Wahl, R. L., Guven, O., \& Skarpeteig, M. I. (2017). Education in emergencies: A review of theory and research. Review of Educational Research, 87(3), 619-658. https://doi.org/10.3102 /0034654316671594.

Burns, M., \& Lawrie, J. (2015). Where It's Needed Most: Quality Professional Development for All Teachers. In M. Burns \& J. Lawrie (Eds.), Inter-Agency Network for Education in Emergencies. New York: InterAgency Network for Education in Emergencies.

Canagarajah, S. (2005). Critical pedagogy in L2 learning and teaching. In E. Hinkel (Ed.), Handbook of research in second language teaching and learning (pp. 931-951). Mahwah: Lawrence Erlbaum Associates.

Chipps J, Pimmer C, Brysiewicz P, Walters F, Linxen S, Ndebele T and Gröhbiel U (2015) Using mobile phones and social media to facilitate education and support for rural-based midwives in South Africa. Curationis 38(2), 1-8. https://doi.org/10.4102/curationis.v38i2.1500.

Cross, R. (2010). Language teaching as sociocultural activity: Rethinking language teacher practice. Modern Language Journal, 94(3), 434-452. https://doi.org/10.1111/j.1540-4781.2010.01058.x.

Dahya, N., Dryden-Peterson, S., Douhaibi, D., \& Arvisais, O. (2019). Social support networks, instant messaging, and gender equity in refugee education. Information, Communication \& Society, 22(6), 774-790. https://doi.org/10.1080/1369118X.2019.1575447.

Devlin, M., \& McKay, J. (2016). Teaching students using technology: Facilitating success for students from low socioeconomic status backgrounds in Australian universities. Australasian Journal of Educational Technology, 32(1), 92-106.

Edge, J. (2011). The reflexive teacher educator in TESOL: Roots and wings. Abingdon: Routledge.

Elliott, D. (2009). Internet technologies and language teacher education. In M. Thomas (Ed.), Handbook of Research on Web 2.0 and Second Language Learning (pp. 432-450). London: Information Science Reference.

Farrell, T. S. C. (2007). Reflective language teaching: From research to practice. New York: Continuum.

Fassetta, G., Imperiale, M. G., Frimberger, K., Attia, M., \& al-Masri, N. (2017). Online teacher training in a context of forced immobility: The case of Gaza, Palestine. European Education, 49(2-3), 133-150. https://doi.org/10.1080/10564934.2017.1315538.

Freire, P. (1970/1996). Pedagogy of the oppressed. London: Penguin Books.

Habibi, A., Mukminin, A., Riyanto, Y., et al. (2018). Building an online community: Student teachers' perceptions on the advantages of using social networking services in a teacher education program. Turkish Online Journal of Distance Education, 19(1), 46-61.

Hawkins, M., \& Norton, B. (2009). Critical language teacher education. In A. Burns \& J. C. Richards (Eds.), Cambridge guide to second language teacher education (pp. 30-39). Cambridge: Cambridge University Press. 
Johnson, K. E. (2006). The sociocultural turn and its challenges for second language teacher education. TESOL Quarterly, 40(1), 235-257.

Karam, F. J., Kibler, A. K., \& Yoder, P. J. (2017). "Because even us, Arabs, now speak English”: Syrian refugee teachers' investment in English as a foreign language. International Journal of Intercultural Relations, 60, 169-182. https://doi.org/10.1016/j.ijintrel.2017.04.006.

Kirk, J., \& Winthrop, R. (2007). Promoting quality education in refugee contexts: Supporting teacher development in northern Ethiopia. International Review of Education, 53(5-6), 715-723. https://doi. org/10.1007/s11159-007-9061-0.

Kumar Singh, P. (2017). WhatsApp Community of Practice (CoP) for teachers. In G. Motteram (Ed.), Teaching and technology: Case studies from India (pp. 22-23). British Council: New Delhi.

Kumaravadivelu, B. (2001). Toward a postmethod pedagogy. TESOL Quarterly, 35(4), 537-560. https://doi. org $/ 10.2307 / 3588427$.

Kumaravadivelu, B. (2006). TESOL methods: Changing tracks, challenging trends. TESOL Quarterly, 40(1), 59-81.

Kyounghye, S., \& You-Kyung, H. (2013). Online teacher collaboration: A case study of voluntary collaboration in a teacher-created online community. KEDI Journal of Educational Policy, 10(2), 221-242 Available at: http://proxy-remote.galib.uga.edu/login?url=http://search.ebscohost.com/login.aspx?direct= true $\& \mathrm{db}=$ ehh $\& A N=93608361 \&$ site $=$ ehost-live.

Lowenthal, P. R., \& Dennen, V. P. (2017). Social presence, identity, and online learning: Research development and needs. Distance Education, 38(2), 137-140. https://doi.org/10.1080/01587919.2017.1335172.

Macià, M., \& García, I. (2016). Informal online communities and networks as a source of teacher professional development: A review. Teaching and Teacher Education, 55, 291-307. https://doi.org/10.1016/j. tate.2016.01.021.

Mann, S. (2005). The language teacher's development. Language Teaching, 38(3), 103-118. https://doi. org/10.1017/S0261444805002867.

McAleavy, T., Hall-Chen, A., Horrocks, S., \& Riggall, A. (2018). Technology-supported professional development for teachers: Lessons from developing countries. Reading: Education Development Trust https://www.educationdevelopmenttrust.com/our-research-and-insights/research/technology-supportedprofessional-development-for.

Mendenhall, M. (2016). Strengthening teacher professional development: Local and global communities of practice in Kakuma Refugee Camp, Kenya. https://static1.squarespace.com/static/583afl fb414fb5b3977 b6f89/t/59bdbadc8419c21c1bd35570/1505606367450/11_PromisingPractices_Teachers+for+Teachers_ WEB.pdf.

Mendenhall, M., Skinner, M., Collas, S., \& French, S. (2018). Expanding teacher support through Mobile mentoring in Kakuma refugee camp: Benefits and challenges. Current Issues in Comparative Education, 20(2), 9-23.

Moon, B. (2007). Research analysis: attracting, developing and retaining effective teachers: a global overview of current policies and practices. http://oro.open.ac.uk/9752/.

Moore, M. G. (1993). Theory of transactional distance. In D. Keegan (Ed.), Theoretical principles of distance education (pp. 22-38). London: Routledge.

Motteram, G. (2019). Videoconferencing tools as mediating artefacts in English language teacher development in challenging contexts. The Journal of Educators Online, 16(1). https://www.thejeo. com/archive/2019_16_1/motteram.

Motteram, G., \& Dawson, S. (2019). Resilience and language teacher development in challenging contexts: Supporting teachers through social media. London: The British Council. https://www.teachingenglish. org.uk/article/resilience-language-teacher-development-challenging-contexts-supporting-teachersthrough.

Motteram, G., Al-Masri, N., Hamouda, H. \& Omarali, S. (2020). Exploring mobile support for English language teachers in a context of conflict: Syrian refugee teachers in Jordan. In Fassetta, G., Al-Masri, N. \& Phipps, A. (Eds.). Multilingual online academic collaborations as resistance: Crossing impassable borders. Bristol: Multilingual Matters.

Nedungadi, P., Mulki, K., \& Raman, R. (2017). Improving educational outcomes \& reducing absenteeism at remote villages with mobile technology and WhatsAPP: Findings from rural India. Education and Information Technologies, 23, 113-127. https://doi.org/10.1007/s10639-017-9588-z.

Prabhu, N. S. (1990). There is no best method-why? TESOL Quarterly, 24(2), 161-176. https://doi. org/10.2307/3586897.

Qi, G. Y., \& Yuping, W. (2017). Investigating the building of a WeChat based community of practice for language teachers' professional development. Innovation in Language Learning and Teaching, 12(1), 72-88. https://doi.org/10.1080/17501229.2018.1418635. 
Reeves Ring, H., \& West, A. (2015). Teacher retention in refugee and emergency settings: The state of the literature. International Education Journal: Comparative Perspectives, 14(3), 106-121.

Richards, J. C. (2008). Second language teacher education today. RELC Journal, 39(2), 158-177. https://doi. org/10.1177/0033688208092182.

Richardson, E. (2018). Teachers of refugees: A review of the literature. Reading: Education Development Trust. https://eric.ed.gov/?id=ED588878.

Schön, D. (1983). The reflective practitioner: How professionals think in action. Aldershot: Ashgate Publishing.

Shohel, M. M. C., \& Power, T. (2010). Introducing mobile technology for enhancing teaching and learning in Bangladesh: Teacher perspectives. Open Learning, 25(3), 201-215. https://doi.org/10.1080 /02680513.2010.511953.

Shulman, L. S. (1987). Knowledge and teaching: Foundations of the new reform. Harvard Educational Review, 57(1), 1-22.

Singh, G., \& Richards, J. C. (2006). Teaching and learning in the language teacher education course room: A critical sociocultural perspective. RELC Journal, 37(2), 149-175. https://doi.org/10.1177 /0033688206067426.

Wenger, E. (1998). Communities of practice: Learning, meaning, identity. Cambridge: Cambridge University Press.

Winthrop, R., \& Kirk, J. (2002). Teacher development and student well-being. Forced Migration Review, 1(1), 18-22.

World Bank. (2010). Teacher policy and management in fragile and conflict-affected situations. A review of issues, policies and experiences. Addis Abada, Ethiopia.

World Food Program USA. (2019). 10 facts about the Syrian refugee Crisis in Jordan. Online at https://www. wfpusa.org/stories/10-facts-about-the-syrian-refugee-crisis-in-jordan/ Accessed 3 ${ }^{\text {rd }}$ December 2019.

Publisher's note Springer Nature remains neutral with regard to jurisdictional claims in published maps and institutional affiliations. 